\title{
Carbon dioxide embolism during endoscopic saphenous vein harvesting in coronary artery bypass surgery
}

\author{
Tzu-Yu Lin, MD \\ Kuan-Ming Chiu, MD \\ Ming-Jiuh Wang, MD, $\mathrm{PhD}^{\mathrm{C}}$ \\ Shu-Hsun Chu, MD
}

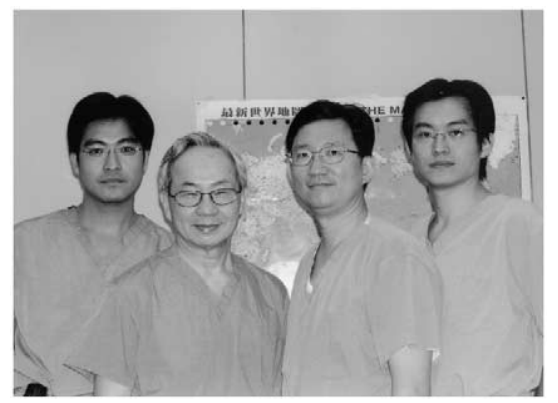

Left to right: Drs Lin, Chu, Wang, and Chiu

\footnotetext{
From the Departments of Anesthesia ${ }^{a}$ and Surgery, ${ }^{\mathrm{b}}$ Far Eastern Memorial Hospital, and the Department of Anesthesiology, National Taiwan University Hospital and National Taiwan University College of Medicine, Taipei, Taiwan.

Received for publication June 12, 2003; revisions requested July 1, 2003; revisions received July 6, 2003; accepted for publication July 21, 2003.

Address for reprints: Dr Ming-Jiuh Wang, Associate Professor, Department of Anesthesiology, National Taiwan University Hospital and National Taiwan University College of Medicine, 7 Chung Shan South Road, Taipei, Taiwan 100 (E-mail: canon@ha.mc.ntu.edu.tw).

J Thorac Cardiovasc Surg 2003;126:2011-5

Copyright (C) 2003 by The American Association for Thoracic Surgery

0022-5223/2003\$30.00+0

doi:10.1067/S0022-5223(03)01323-0
}

Objectives: Our objectives were to determine the incidence and severity and the time course of the $\mathrm{CO}_{2}$ embolism during endoscopic saphenous vein harvesting with $\mathrm{CO}_{2}$ insufflation in coronary artery bypass surgery with transesophageal echocardiography monitoring.

Methods: Four hundred three consecutive patients scheduled for off-pump coronary artery bypass grafting surgery or femoral-to-popliteal artery bypass grafting surgery were prospectively studied. Multiplane transesophageal echocardiography with a new transgastric view was used to monitor $\mathrm{CO}_{2}$ bubbles in the inferior vena cava and hepatic vein.

Results: $\mathrm{CO}_{2}$ embolisms occurred in $17.1 \%$ of patients. Minimal, moderate, and massive $\mathrm{CO}_{2}$ embolisms occurred in $13.1 \%, 3.5 \%$, and $0.5 \%$, respectively. The occurrence of moderate and massive $\mathrm{CO}_{2}$ embolisms was frequently associated with the surgical manipulation of branches of saphenous veins. No significant risk factors were identified in multiple logistic regression analysis.

Conclusion: The incidence of significant $\mathrm{CO}_{2}$ embolism during endoscopic saphenous vein harvesting with $\mathrm{CO}_{2}$ insufflation procedures was more than $4 \%$. Continuous transesophageal echocardiographic monitoring of the $\mathrm{CO}_{2}$ bubbles in the inferior vena cava is essential in early detection and can help to prevent the development of significant $\mathrm{CO}_{2}$ embolisms in these patients.

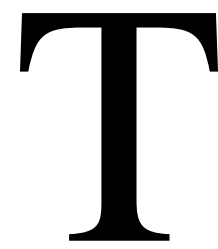
he great saphenous vein used in coronary artery bypass grafting (CABG) surgery is conventionally harvested by means of the open technique. Recently, endoscopic saphenous vein harvesting $(\mathrm{EVH})$ was introduced into cardiac surgical practice, and it was shown to be associated with fewer wound complications, ${ }^{1}$ shorter hospital stay, less postoperative pain, and better patient satisfaction. ${ }^{2,3} \mathrm{CO}_{2}$ insufflation was used in endoscopic surgery for a long time, and it was used in some EVH instrument systems to create a subcutaneous tunnel and to facilitate the harvest of the great saphenous vein in CABG surgery. The use of $\mathrm{CO}_{2}$ during EVH was reported to reduce vein trauma and hematoma. ${ }^{4}$ The incidence of the venous $\mathrm{CO}_{2}$ embolism is reported to be very low in laparoscopic surgery, ${ }^{5,6}$ whereas the incidence of $\mathrm{CO}_{2}$ embolisms during $\mathrm{EVH}$ with $\mathrm{CO}_{2}$ insufflation $\left(\mathrm{EVHCO}_{2}\right)$ was not known. $\mathrm{CO}_{2}$ embolism did not occur in more than 600 patients reported to receive EVHCO $_{2}^{4,7-10}$ in CABG surgery. However, a case report of life-threatening $\mathrm{CO}_{2}$ embolisms caused concern about the safety of $\mathrm{EVHCO}_{2}{ }^{11}{ }^{11}$ Transesophageal echocardiography (TEE) was suggested to be the most sensitive tool in detecting $\mathrm{CO}_{2}$ embolism when compared with end-tidal $\mathrm{CO}_{2}$ and pulmonary artery pressure monitoring. The purpose of this study was to investigate the incidence and severity of $\mathrm{CO}_{2}$ embolism during $\mathrm{EVHCO}_{2}$ in patients undergoing $\mathrm{CABG}$ with TEE monitoring. 


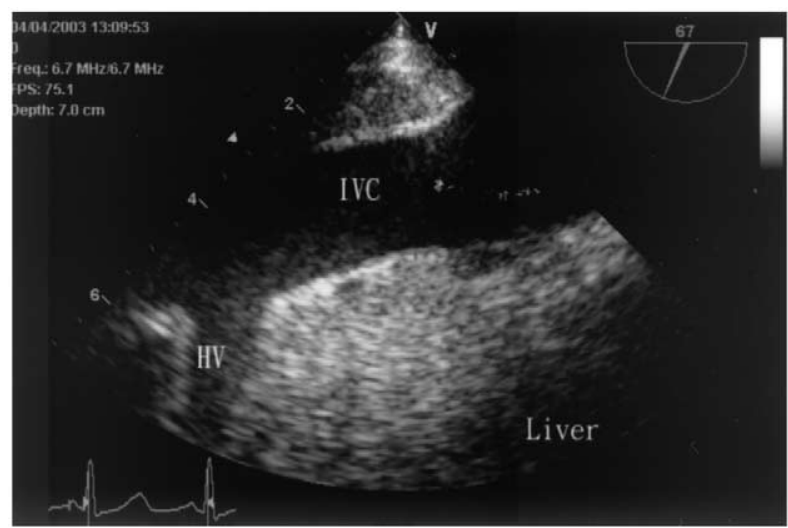

Figure 1. Transgastric multiplane TEE view to monitor the $\mathrm{CO}_{2}$ embolism during $\mathrm{EVHCO}_{2}$. $\mathrm{HV}$, Hepatic vein.

\section{Methods}

Since July 2001, when $\mathrm{EVHCO}_{2}$ in CABG surgery was started in our hospital, the surgeons and a physician assistant took 3 months to become familiar with this new technique in the first 50 patients. After the maturation of the technique, 405 consecutive patients scheduled for CABG surgery or femoral-to-popliteal artery bypass grafting (FPABG) were prospectively studied. The study was approved by the institutional ethics review board, and written informed consent was obtained from all patients. Patients were excluded if they had prior saphenous vein harvesting for peripheral arterial occlusive disease or CABG surgery. All patients received a preoperative dose of first-generation cephalosporin or vancomycin for antibiotic prophylaxis.

General anesthesia was induced in all patients with 3 to $5 \mu \mathrm{g} / \mathrm{kg}$ fentanyl and $5 \mathrm{mg} / \mathrm{kg}$ thiopental, and $0.1 \mathrm{mg} / \mathrm{kg}$ rocuronium was used to facilitate intubations. Standard monitors include pulse oximetry, end-tidal $\mathrm{CO}_{2}$, arterial line, rectal temperature, and the central venous or pulmonary artery catheters. An adult multiplane TEE probe (6T, GE Vingmed Medical) was inserted after anesthetic induction and intubation. After the routine TEE evaluation of the cardiac function and regional wall motion of the myocardium, the probe was advanced deeper into the stomach and rotated clockwise. The inferior vena cava (IVC) within the liver was identified to avoid possible imaging interference from the fluid or injection of drugs from the superior vena cava, and the angle of the multiplane echocardiographic beam was adjusted between $30^{\circ}$ and $70^{\circ}$ to visualize the long axis of the IVC and hepatic vein (Figure 1). When the views of the IVC and the hepatic vein were obtained, the TEE probe was fixed at that position. The IVC was monitored continuously with TEE by an anesthesiologist, and a super VHS tape recorder was used to record the TEE images during EVH. Any appearance of gas bubbles was registered, and the videotape was reviewed by another anesthesiologist who is a qualified perioperative TEE examiner (Dr Wang) to confirm the findings.

There was no preoperative mapping of the venous system. All of the EVH procedures were performed by a surgeon or a physician assistant who had been trained by the manufacturer of the EVH system and had performed these procedures on more than 50 patients. The Vasoview Uniport System (Guidant) was used in all patients, with the vein dissector and flexible bipolar scissors in-
TABLE 1. Demographics of patients

\begin{tabular}{lc}
\hline Patient characteristics & $\mathbf{n}=\mathbf{4 0 3}$ \\
\hline Sex (M:F) & $279: 124$ \\
Age (y) & $65.5 \pm 10.9$ \\
Body weight $(\mathrm{kg})$ & $64.8 \pm 11.3$ \\
Body height (cm) & $160.5 \pm 8.3$ \\
Preoperative IABP use & $49(12.2 \%)$ \\
Types of operation & \\
Elective off-pump CABG & $292(72.5 \%)$ \\
Emergency off-pump CABG & $42(10.4 \%)$ \\
CABG + valve & $53(13.2 \%)$ \\
CABG with partial CPB & $6(1.5 \%)$ \\
PAOD & $10(2.4 \%)$ \\
\hline
\end{tabular}

Values are shown as means \pm SD. IABP, Intra-aortic balloon counterpulsation; $C A B G$ + valve, $C A B G$ with valvular reconstruction or replacement; $C P B$, cardiopulmonary bypass; $P A O D$, peripheral arterial occlusive disease.

troduced through a trocar. The initial skin incision was made just above the joint line and was $2 \mathrm{~cm}$ long in a longitudinal fashion. After insertion of a port to achieve the air seal through the incision, $\mathrm{CO}_{2}$ was insufflated at a pressure of $15 \mathrm{~mm} \mathrm{Hg}$ to create a subcutaneous tunnel. The great saphenous vein was dissected with the working endoscope up to the groin region. The branches of the saphenous vein were identified and charred and then divided to avoid bleeding and possible $\mathrm{CO}_{2}$ embolization with bipolar scissors. Another skin incision was made over the proximal end of the vein, and the saphenous vein was ligated proximally and divided. During the EVH procedure monitored with TEE, any occurrence of bubbles was noted to the surgeons. If dozens of $\mathrm{CO}_{2}$ bubbles were found on the TEE monitor, $\mathrm{CO}_{2}$ insufflation was stopped immediately. The $\mathrm{CO}_{2}$ insufflation was resumed only after careful examination of the possible entrance of the saphenous veins; otherwise, the vein harvesting was completed without the use of $\mathrm{CO}_{2}$.

Statistical analysis of continuous variables among different groups was done with 1-way analysis of variance. Multiple logistic regression analysis was used to determine the risk factors of $\mathrm{CO}_{2}$ embolism during $\mathrm{EVHCO}_{2}$.

\section{Results}

Table 1 summarizes the demographic data of the patients. Two patients were excluded from the study because of conversion to the open or bridging method of vein harvesting as a result of technical difficulties. The operative variables are shown in Table 2. The status of $\mathrm{CO}_{2}$ embolisms detected with TEE during $\mathrm{EVHCO}_{2}$ were classified as minimal, moderate, and massive according to the amount of $\mathrm{CO}_{2}$ bubbles identified in the IVC. In patients with minimal $\mathrm{CO}_{2}$ embolism, less than $5 \mathrm{CO}_{2}$ bubbles were found during $\mathrm{EVHCO}_{2}$ (Figure 2). If dozens of $\mathrm{CO}_{2}$ bubbles were found in the IVC (Figure 3), patients were assigned to the moderate $\mathrm{CO}_{2}$ embolism group. If there were numerous $\mathrm{CO}_{2}$ bubbles in the IVC, right atrium, right ventricle, or pulmonary artery (Figure 4), patients were assigned to the massive $\mathrm{CO}_{2}$ embolism group. 


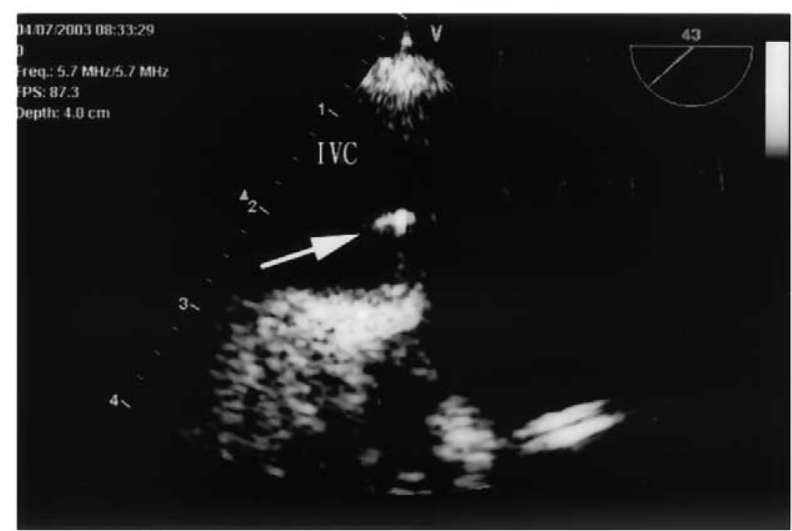

Figure 2. Transgastric multiplane TEE view of minimal $\mathrm{CO}_{2} \mathrm{em}$ bolism during $\mathrm{EVHCO}_{2}$. A single $\mathrm{CO}_{2}$ bubble (arrow) was detected with TEE.

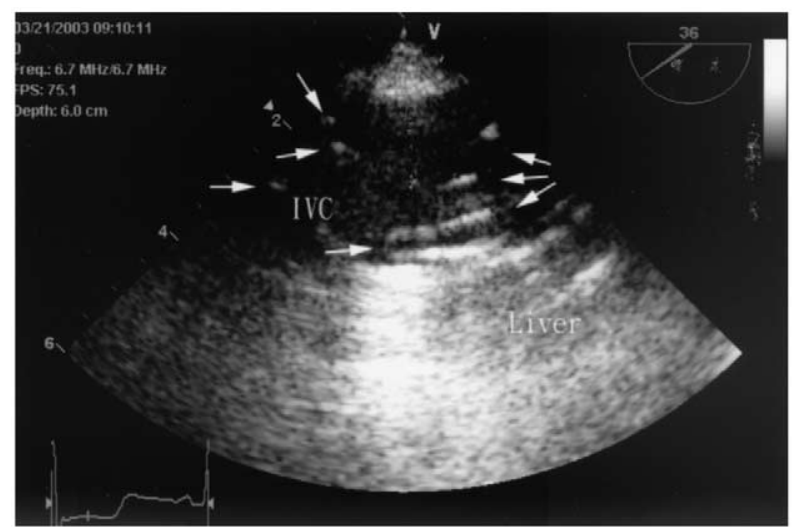

Figure 3. Transgastric multiplane TEE view of moderate $\mathrm{CO}_{2}$ embolism during $\mathrm{EVHCO}_{2}$. Dozens of $\mathrm{CO}_{2}$ bubbles (arrows) were detected with TEE.

$\mathrm{CO}_{2}$ bubbles in the IVC were found in 69 (17.1\%) patients. Minimal, moderate, and massive amounts of $\mathrm{CO}_{2}$ bubbles were found in $53(13.1 \%), 14(3.5 \%)$, and $2(0.5 \%)$ patients, respectively (Table 3$)$. In the 2 patients with massive $\mathrm{CO}_{2}$ embolisms, one patient underwent FPABG, and the other patient underwent elective off-pump CABG surgery. In both cases, massive $\mathrm{CO}_{2}$ embolism occurred suddenly, even though $\mathrm{CO}_{2}$ insufflation was stopped immediately after the echocardiographic detection of $\mathrm{CO}_{2}$ bubbles. Blood pressure, end-tidal $\mathrm{CO}_{2}$, oxygen saturation, and cardiac output all decreased immediately at that time. The patient who underwent FPABG was rescued successfully with phenylephrine and epinephrine, and hemodynamic stability was restored rapidly. The other patient was not responsive to pharmacologic agents and required emergency cardiopulmonary bypass support to complete the $\mathrm{CABG}$ surgery.

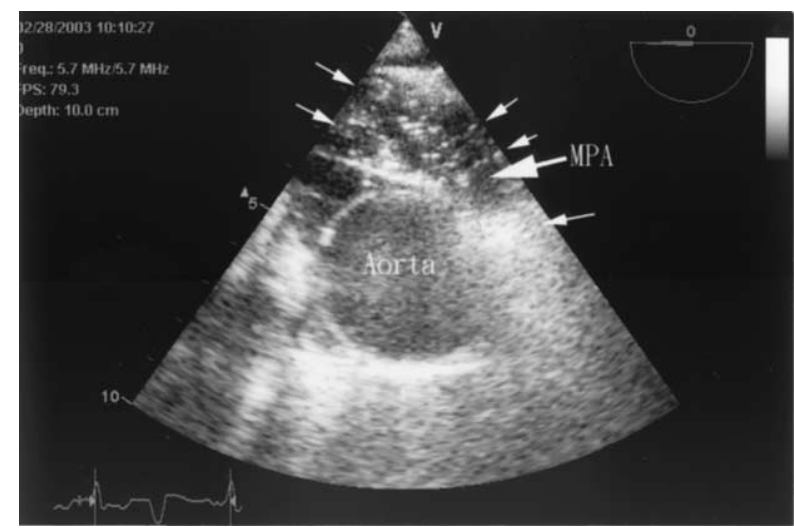

Figure 4. Transgastric multiplane TEE view of massive $\mathrm{CO}_{2}$ embolism during $\mathrm{EVHCO}_{2}$. Numerous $\mathrm{CO}_{2}$ bubbles were found in the main and right pulmonary artery. MPA, Main pulmonary artery.

TABLE 2. Operative variables $(n=403)$

\begin{tabular}{lccc}
\hline & Minimum & Maximum & Mean \pm SD \\
\hline Operation time (min) & 130 & 269 & $232.4 \pm 28.9$ \\
Harvest time (min) & 15.00 & 45.00 & $25.9 \pm 7.0$ \\
Vein harvest length (cm) & 25.00 & 32.00 & $27.8 \pm 2.9$ \\
No. of bypass grafts & 1.00 & 5.00 & $3.5 \pm 0.6$ \\
\hline
\end{tabular}

\section{TABLE 3. Incidence and severity of $\mathrm{CO}_{2}$ embolism}

\begin{tabular}{lc}
\hline Status of $\mathrm{CO}_{2}$ embolism & \\
\hline Incidence of $\mathrm{CO}_{2}$ embolism & $69(17.1 \%)$ \\
Severity of $\mathrm{CO}_{2}$ embolism & \\
Nil & $334(82.9 \%)$ \\
Minimal & $53(13.1 \%)$ \\
Moderate & $14(3.5 \%)$ \\
Massive & $2(0.5 \%)$ \\
\hline
\end{tabular}

The intraoperative end-tidal $\mathrm{CO}_{2}$ concentrations during the $\mathrm{EVHCO}_{2}$ period did not differ among patients without $\mathrm{CO}_{2}$ embolism $(31.4 \pm 2.4 \mathrm{mmHg})$ and patients with minimal and moderate-to-massive numbers of $\mathrm{CO}_{2}$ bubbles ( $31.6 \pm 2.4$ and $32.4 \pm 2.2 \mathrm{~mm} \mathrm{Hg}$, respectively) in the IVC. The appearance of $\mathrm{CO}_{2}$ bubbles in the IVC was associated with the division of the tributaries of the saphenous veins in $57 \%$ of patients with minimal $\mathrm{CO}_{2}$ embolism, whereas it was associated with surgical division of saphenous vein branches in $93 \%$ of patients with moderate or massive $\mathrm{CO}_{2}$ embolism. The results of multiple logistic regression analysis did not reveal any of the possible risk factors, including the length of harvest time, varicose saphenous veins, diabetes mellitus, and cerebral vascular accidents, to be significant in the development of moderate and massive $\mathrm{CO}_{2}$ embolism during $\mathrm{EVHCO}_{2}$. 


\section{Discussion}

We demonstrated that $\mathrm{CO}_{2}$ embolization of different severities could be detected with TEE in $17.1 \%$ of patients undergoing $\mathrm{EVHCO}_{2}$. In most of these patients, only a very tiny amount of $\mathrm{CO}_{2}$ was found to enter the circulation. However, moderate numbers of $\mathrm{CO}_{2}$ bubbles were detected in the IVC in $3.5 \%$ of patients, and massive $\mathrm{CO}_{2}$ embolism, which led to significant hemodynamic alterations, occurred in $0.5 \%$ of patients. The incidence of the venous $\mathrm{CO}_{2}$ embolism during laparoscopic surgery was reported to be very low $(0.02 \%-0.00013 \%)$, 5,6 whereas the incidence of venous $\mathrm{CO}_{2}$ embolism during endoscopic saphenectomy was not known. In 5 separate studies that compared the $\mathrm{EVHCO}_{2}$ in CABG surgery with the traditional open or bridging method of saphenous vein harvesting in more than 600 patients, ${ }^{4,7-10}$ no $\mathrm{CO}_{2}$ embolisms that caused hemodynamic alterations were reported. However, monitoring of $\mathrm{CO}_{2}$ bubbles was not done in all these studies. On the other hand, life-threatening $\mathrm{CO}_{2}$ embolisms were reported in 3 case reports in patients undergoing $\mathrm{EVHCO}_{2}{ }^{11-13}$ Our study showed that minimal $\mathrm{CO}_{2}$ embolism occurred frequently during $\mathrm{EVHCO}_{2}$ and confirmed that there was a risk of massive $\mathrm{CO}_{2}$ embolism in more than $0.5 \%$ of patients. The continuous monitoring of $\mathrm{CO}_{2}$ bubbles with TEE in our study ensured the immediate cessation of $\mathrm{CO}_{2}$ insufflation after its detection during $\mathrm{EVHCO}_{2}$, although significant hemodynamic alterations still occurred in 2 of our patients.

The mechanisms of $\mathrm{CO}_{2}$ embolism during endoscopic procedures were suggested to include absorption of $\mathrm{CO}_{2}$ into the circulation or direct entry into an injured vessel. In patients with only minimal $\mathrm{CO}_{2}$ embolism, it seemed that both mechanisms were possible to be involved in the entry of $\mathrm{CO}_{2}$ bubbles in the circulation. Because the appearance of $\mathrm{CO}_{2}$ bubbles was most frequently associated with the division of the tributaries of the saphenous veins in patients with moderate and massive $\mathrm{CO}_{2}$ embolization, direct entry of $\mathrm{CO}_{2}$ into the injured saphenous vein or its branches was the most likely mechanism of $\mathrm{CO}_{2}$ embolism in these patients. ${ }^{11-13}$ In fact, in 2 of the 3 case reports of $\mathrm{CO}_{2}$ embolisms during $\mathrm{EVHCO}_{2}$ in the literature and in our patients with massive $\mathrm{CO}_{2}$ embolisms, the $\mathrm{CO}_{2}$ embolisms and sudden cardiovascular collapse all occurred when the branches of the saphenous vein were manipulated or divided. These findings suggested that $\mathrm{CO}_{2}$ at a pressure of 15 $\mathrm{mm} \mathrm{Hg}$ was introduced into the venous circulation through the injured vessel directly. Because the amount of $\mathrm{CO}_{2}$ entered into the circulation was dependent on the pressure difference of the $\mathrm{CO}_{2}$ insufflation and the saphenous vein, ${ }^{11}$ whether the reduction of the insufflation pressure might reduce the incidence of $\mathrm{CO}_{2}$ embolization requires further investigation.

TEE was found to be the most sensitive tool to detect venous $\mathrm{CO}_{2}$ embolism. ${ }^{14}$ Because the administration of fluid and pharmacologic agents during surgical intervention caused some turbulent flow, simulating the gas bubbles in the right atrium, the traditional TEE view of the right atrium was not ideal for monitoring the appearances of the $\mathrm{CO}_{2}$ bubbles. To solve this problem, we developed a new transgastric IVC view to monitor the $\mathrm{CO}_{2}$ bubbles in the IVC during $\mathrm{EVHCO}_{2}$ in patients undergoing CABG. In this TEE view the long axis of the IVC and the confluence with the hepatic vein could be easily and clearly obtained in all of our patients. The short distance from the probe to the IVC and the very high resolution and sensitivity in this TEE view ensured that even a single $\mathrm{CO}_{2}$ bubble in the IVC could be clearly seen. The finding that end-tidal $\mathrm{CO}_{2}$ did not differ between patients with or without $\mathrm{CO}_{2}$ embolism suggested that $\mathrm{CO}_{2}$ absorption did not play an important role in moderate or massive $\mathrm{CO}_{2}$ embolism during $\mathrm{EVHCO}_{2}$. In fact, in both patients with massive $\mathrm{CO}_{2}$ embolism, the end-tidal $\mathrm{CO}_{2}$ decreased suddenly after the detection of a massive $\mathrm{CO}_{2}$ embolism by means of TEE. It was the massive $\mathrm{CO}_{2}$ embolisms with "gas lock" in the right atrium and pulmonary artery that led to right ventricular failure and a sudden decrease of cardiac output and end-tidal $\mathrm{CO}_{2}$.

The treatment of life-threatening $\mathrm{CO}_{2}$ embolisms in patients who underwent $\mathrm{EVHCO}_{2}$ and CABG surgery include immediate cessation of $\mathrm{CO}_{2}$ insufflation, rapid volume expansion, administration of vasopressors and inotropic agents to maintain cardiac output, use of intra-aortic balloon counterpulsation, and cardiopulmonary bypass to maintain the hemodynamic stability for the diseased heart. Although significant hemodynamic alterations still developed after immediate detection of $\mathrm{CO}_{2}$ bubbles and the cessation of $\mathrm{CO}_{2}$ insufflation in 2 of our patients, for the other 14 patients, the early detection of $\mathrm{CO}_{2}$ bubbles with an immediate stopping of $\mathrm{CO}_{2}$ insufflation and careful examination of the surgical field successfully prevented the occurrence of massive $\mathrm{CO}_{2}$ embolism and right ventricular dysfunction. $\mathrm{EVHCO}_{2}$ has been shown not only to reduce postoperative wound pain and infection rates in patients undergoing CABG but also to reduce vein injury and hematoma when compared with the EVH procedures without use of $\mathrm{CO}_{2}{ }^{4}$ With the introduction of the off-pump CABG technique, it became popular to use the combination of both methods to reduce postoperative morbidity and mortality in the patients with coronary artery disease. Our findings indicated that TEE monitoring of the IVC during $\mathrm{EVHCO}_{2}$ in $\mathrm{CABG}$ surgery was very valuable in reducing the potential risks of $\mathrm{CO}_{2}$ embolisms during the procedure.

We conclude that moderate $\mathrm{CO}_{2}$ embolisms occurred in about $4 \%$ of patients and were frequently associated with surgical injury to the branches of the great saphenous vein, and the continuous monitoring of the IVC with the new TEE view is essential in early detection and to help prevent the 
development of significant $\mathrm{CO}_{2}$ embolisms during $\mathrm{EVHCO}_{2}$ procedures.

\section{References}

1. Allen KB, Griffith GL, Heimansohn DA, Robison RJ, Matheny RG, Schier JJ, et al. Endoscopic versus traditional saphenous vein harvesting: a prospective, randomized trial. Ann Thorac Surg. 1998;66:26-31.

2. Kiaii B, Moon BC, Massel D, Langlois Y, Austin TW, Willoughby A, et al. A prospective randomized trial of endoscopic versus conventional harvesting of the saphenous vein in coronary artery bypass surgery. J Thorac Cardiovasc Surg. 2002;123:204-12.

3. Crouch JD, O'Hair DP, Keuler JP, Barragry TP, Werner PH, Kleinman LH. Open versus endoscopic saphenous vein harvesting: wound complications and vein quality. Ann Thorac Surg. 1999;68:1513-6.

4. Chavanon O, Ducharme B, Carrier M, Cartier R, Hebert Y, Page P, et al. Endoscopic saphenectomy for coronary artery bypass surgery: comparison of two techniques with and without carbon dioxide insufflation. Can J Cardiol. 2000;16:757-61.

5. Herron DM, Vernon JK, Gryska PV, Reines HD. Venous gas embolism during endoscopy. Surg Endosc. 1999;13:276-9.

6. Philips J, Keith D, Hulka B, Keith L. Gynecologic laparoscopy in 1975. J Reprod Med. 1976;6:105-17.

7. Patel AN, Hebeler RF, Hamman BL, Hunnicutt C, Williams M, Liu L, et al. Prospective analysis of endoscopic vein harvesting. Am J Surg. 2001;182:716-9.
8. Vrancic JM, Piccinini F, Vaccarino G, Iparraguirre E, Albertal J, Navia D. Endoscopic saphenous vein harvesting: initial experience and learning curve. Ann Thorac Surg. 2000;70:1086-9.

9. Carpino PA, Khabbaz KR, Bojar RM, Rastegar H, Warner KG, Murphy RE, et al. Clinical benefits of endoscopic vein harvesting in patients with risk factors for saphenectomy wound infections undergoing coronary artery bypass grafting. $J$ Thorac Cardiovasc Surg. 2000;119:69-75.

10. Felisky CD, Paull DL, Hill ME, Hall RA, Ditkoff M, Campbell WG, et al. Endoscopic greater saphenous vein harvesting reduces the morbidity of coronary artery bypass surgery. Am J Surg. 2002;183:576-9.

11. Chavanon O, Tremblay I, Delay D, Bouveret A, Blain R, Perrault LP. Carbon dioxide embolism during endoscopic saphenectomy for coronary artery bypass surgery. J Thorac Cardiovasc Surg. 1999;118: 557-8.

12. Lin SM, Chang WK, Tsao CM, Ou CH, Chan KH, Tsai SK. Carbon dioxide embolism diagnosed by transesophageal echocardiography during endoscopic vein harvesting for coronary artery bypass grafting. Anesth Analg. 2003;96:683-5.

13. Banks TA, Manetta F, Glick M, Graver LM. Carbon dioxide embolism during minimally invasive vein harvesting. Ann Thorac Surg. 2002; 73:296-7.

14. Couture P, Boudreault D, Derouin M, Allard M, Lepage Y, Girard D, et al. Venous carbon dioxide embolism in pigs: an evaluation of end-tidal carbon dioxide, transesophageal echocardiography, pulmonary artery pressure, and precordial auscultation as monitoring modalities. Anesth Analg. 1994;79:876-3. 